\title{
Utilization of Extracorporeal Membrane Oxygenation for Pulmonary Toxicity Caused by Inhaled Synthetic Cannabinoid. A Harbinger of Future Complications Associated with Inhaled Cannabinoid Products
}

\author{
Robert March'1, Paul Guentert1', Elizabeth Kloska-Kearney ${ }^{1}$, David Kwak1 ${ }^{1}$, Cody Yerger1, \\ Michael McBride1, J. R. Majewski', Ross McCauley², Jordan Hatch², Jacob Speybroeck ${ }^{2}$, \\ Allen Betts' ${ }^{2}$ Mat Marsee ${ }^{2}$, Sufyan Zackariya' ${ }^{1}$, Faisal Shariff ${ }^{2}$, Shivani Patel', Ali Sualeh"1, \\ Anthony Thomas ${ }^{1}$, Edward Evans ${ }^{1}$, Donald Westerhausen ${ }^{3}$, Mark Walsh ${ }^{1}$ \\ ${ }^{1}$ Saint Joseph Regional Medical Center, Mishawaka, IN, USA \\ ${ }^{2}$ Indiana University School of Medicine-South Bend, South Bend, IN, USA \\ ${ }^{3}$ Department of Pulmonary and Critical Care Medicine, Methodist Hospital, Indianapolis, IN, USA \\ Email: markwalshmd@gmail.com
}

How to cite this paper: March, R., Guentert, P., Kloska-Kearney, E., Kwak, D., Yerger, C., McBride, M., Majewski, J.R., McCauley, R., Hatch, J., Speybroeck, J., Betts, A., Marsee, M., Zackariya, S., Shariff, F., Patel, S., Sualeh, A., Thomas, A., Evans, E., Westerhausen, D. and Walsh, M. (2020) Utilization of Extracorporeal Membrane Oxygenation for Pulmonary Toxicity Caused by Inhaled Synthetic Cannabinoid. A Harbinger of Future Complications Associated with Inhaled Cannabinoid Products. International Journal of Clinical Medicine, 11, 53-61.

https://doi.org/10.4236/ijcm.2020.112006

Received: January 21, 2020

Accepted: February 10, 2020

Published: February 13, 2020

Copyright (๑) 2020 by author(s) and Scientific Research Publishing Inc. This work is licensed under the Creative Commons Attribution International License (CC BY 4.0).

http://creativecommons.org/licenses/by/4.0/ (c) (i)

Open Access

\begin{abstract}
There has been a dramatic increase in medical complications related to synthetic cannabinoid (SC) use either by water pipe or vaping. The legalization of marijuana in an increasing number of states has also resulted in an increase in a number of complications related not just to marijuana, but in particular, to SC. As a result, there have been recent increased reports of acute pulmonary injury related to inhaled SC products. We describe that rarely endotracheal intubation with mechanical ventilation has been required to treat the acute respiratory distress syndrome (ARDS) and the diffuse alveolar hemorrhage (DAH) associated with the acute toxicity of SC inhalation. We describe the second reported case of successful utilization of mechanical ventilation and extracorporeal membrane oxygenation (ECMO) in order to treat acute pulmonary toxicity caused by SC inhalation by a water pipe. While the exact pathophysiology of these interesting and recent pulmonary complications is unknown, the recent increase in exposure to SC via water pipe systems and vaping suggests that there will be many more cases of patients that will require ECMO as a form of life-saving therapy.
\end{abstract}

\section{Keywords}

Synthetic Cannabinoid, Extracorporeal Membrane Oxygenation, Mechanical Ventilation, Water Pipe, Vaping, Pulmonary Toxicity 


\section{Introduction}

Emergencies related to synthetic cannabinoids (SC) have increased recently in the United States [1] [2] [3]. The legalization of marijuana in states such as Nevada, Maine, Colorado, and California has increased accessibility of SC leading to the presentation of medical complications related to SC [4] [5]. The most common adverse presentations of SC use include nausea, vomiting, anxiety, psychosis, paranoia, and agitation [6] [7] [8] [9]. In addition, there are case series and case reports of stroke, hypertension, cardiac toxicity, and encephalopathy related to SC inhalation. Specifically, there has been a recent increase in reports of respiratory pathology such as acute respiratory distress syndrome (ARDS), diffuse alveolar hemorrhage (DAH), and chronic pulmonary findings associated with inhaled SC use [3] [7] [10] [11]. The acute and chronic findings of direct pulmonary toxicity do not include the depression of respiratory drive caused by SC [4] [5]. In addition to SC induced respiratory depression, there has been a recent increase in cases due to direct pulmonary toxicity not related to aspiration or infection [3] [7] [10]-[15]. In all the reported cases, alveolar hemorrhages developed within 48 hours after SC inhalation suggesting a temporal relation [7] [10]-[15].

Direct pulmonary injury by SC leading to the development of ARDS and $\mathrm{DAH}$ requiring endotracheal intubation has been reported infrequently [7] [10]-[15]. Failure to successfully treat respiratory insufficiency, ARDS, and DAH caused by SC with endotracheal intubation and mechanical ventilation is even rarer. The utilization of Extracorporeal membrane oxygenation (ECMO) to treat such a patient has been reported on only one occasion in abstract form [16]. In this first full case report we describe a 21-year-old woman who developed interstitial pneumonitis which required endotracheal intubation and immediate utilization of ECMO in order to ensure proper gas exchange.

\section{Case Report}

A 21-year-old African American female with no chronic medical problems or past surgical history presented to the emergency department with a 12-hour history of dyspnea and hemoptysis. The previous night she inhaled an undocumented amount of synthetic marijuana, known as K2, from a water pipe. Upon arrival in the emergency department, the patient's symptoms included dyspnea, hemoptysis, throat pain, central chest pain and fatigue. Social history was positive for infrequent inhalation of natural marijuana. The patient reports that this was her first exposure to SC in any form. She had no known allergies.

Initial set of vitals showed $\mathrm{T} 98.5^{\circ} \mathrm{F}, \mathrm{BP} 91 / 55, \mathrm{HR} 99, \mathrm{SpO}_{2} 40 \%-60 \%$, RR 28 . Physical exam in the emergency department revealed a patient in severe distress with diminished breath sounds and diffuse rhonchi.

Chest X-ray revealed left lower lobe and right upper lobe infiltrates. CT Chest showed similar findings with more involvement of the left lung compared to the right (Figure 1). The arterial blood gases were $\mathrm{PO}_{2} 60 \mathrm{~mm} \mathrm{Hg}, \mathrm{PCO}_{2} 52.6 \mathrm{~mm}$ $\mathrm{Hg}$, and $\mathrm{pH} 7.21$. WBC was $23,000 \times 10^{9} / \mathrm{L}$. 


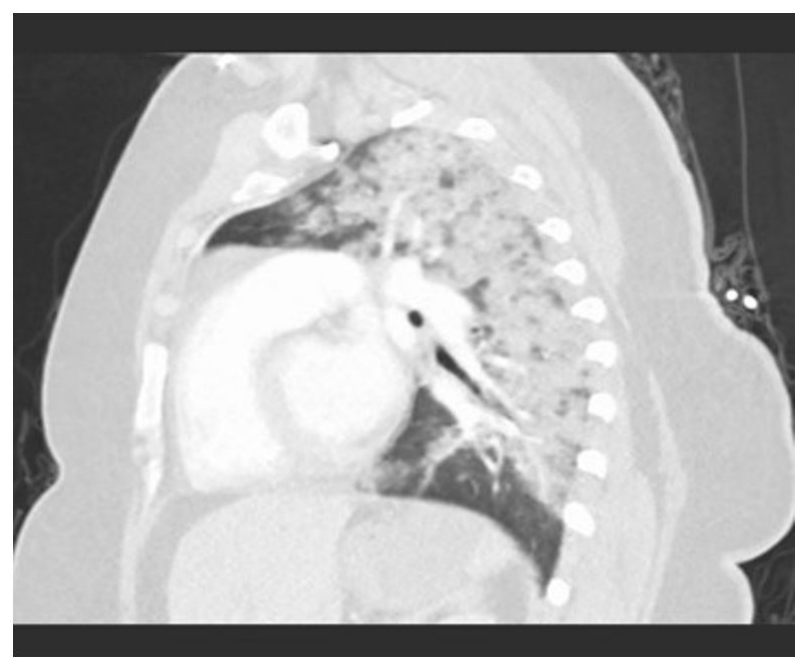

Figure 1. Sagittal CT chest pre-endotracheal intubation prior to initiation of ECMO demostrating diffuse intestinal edema.

The patient was rapidly decompensating, and a bag-valve mask was used before rapid sequence intubation. PEEP was set at $20 \mathrm{~cm} \mathrm{H}_{2} \mathrm{O}$ and the $\mathrm{SpO}_{2}$ never exceed $60 \%$. Despite these settings, she was unable to maintain adequate ventilation and pulse oximetry oxygen saturation remained in a range of $60 \%-70 \%$. At this time, the decision to initiate ECMO was made due to the inability to maintain adequate gas exchange and a 31 French Avalon veno-venous catheter placed (Figure 2). The patient was heparinized prior to initiation. Shortly after, she maintained hemodynamic stability with adequate gas exchange. She was decannulated on day seven, self-extubated on day eight, and discharged on day eleven. CT Chest prior to discharge demonstrated recovery of the acute lung injury (Figure 3). She made an uneventful recovery. Refer to Table 1 for more information.

\section{Discussion}

The increased incidence of complications related to natural and synthetic cannabinoids has drawn great interest [17] [18]. In this recent time frame direct pulmonary toxicity caused by SC has also increased [10] [11] [13] [14] [15]. Our patient developed ARDS and DAH as defined by the Berlin criteria. Since our patient had bilateral ground glass opacities and bilateral air bronchograms that could not be explained by another condition, our patient conformed to the diagnosis of ARDS and DAH [19]. These opacities were not caused by cardiogenic pulmonary edema since the echocardiogram was normal. The patient had significant impairment of gas exchange. Medical history revealed the only risk factor for the development of ARDS and DAH in this patient was SC inhalation that night and late morning prior to admission.

Initial blood gases following endotracheal intubation revealed profound hypoventilation despite high level of pulmonary compliance. During endotracheal intubation, pink, frothy sputum emanated from the trachea. Although 
Table 1. Sociodemographic information and clinical presentation of the patient.

\begin{tabular}{|c|c|}
\hline Sociodemographics & $\begin{array}{l}\text { Age: } 21 \text { y/o } \\
\text { Gender: Female } \\
\text { Onset: SC use } 12 \text { hours before admission } \\
\text { Previous SC Use: Patient denies }\end{array}$ \\
\hline Clinical Presentation & $\begin{array}{l}\text { Temperature: } 98.5 \mathrm{Fahrenheit} \\
\text { Blood Pressure: } 91 / 55 \mathrm{~mm} \mathrm{Hg} \\
\text { Heart Rate: } 99 \text { beats per minute } \\
\mathrm{SpO}_{2}: 40 \% \text { - } 60 \% \text { after rapid sequence intubation } \\
\text { Respiratory Rate: } 28 \text { respirations per minute } \\
\text { Blood Gas: } \mathrm{pO}_{2} 60 \mathrm{mmHg}, \mathrm{pCO}_{2} 52.6 \mathrm{mmHg} \\
\text { pH: } 7.21 \\
\text { Lactate: } 3.8 \mathrm{mmol} / \mathrm{L} \\
\text { Procal: } 0.43 \mathrm{ug} / \mathrm{L} \\
\text { Sed rate: } 23 \mathrm{~mm} / \mathrm{hr} \\
\text { Influenza: } \mathrm{Negative} \\
\text { BUN: } 13 \mathrm{mg} / \mathrm{dL} \\
\text { Creatinine: } 0.74 \mathrm{mg} / \mathrm{dL} \\
\text { Glucose: } 136 \mathrm{mg} / \mathrm{dL} \\
\text { CO }{ }_{2}: 24 \mathrm{~mm} \mathrm{Hg} \\
\text { Chloride: } 104 \mathrm{mEq} / \mathrm{L} \\
\text { Potassium: } 3.8 \mathrm{mEq} / \mathrm{L} \\
\text { Sodium: } 139 \mathrm{mEq} / \mathrm{L} \\
\text { Leukocyte Count: } 23,000 \times 10^{9} / \mathrm{L} \\
\text { Base Deficit: } 7 \\
\text { Echocardiogram: Negative } \\
\text { Clinical Observations: Acute respiratory distress with } \\
\text { frothy pink sputum arising from airway during intubation }\end{array}$ \\
\hline $\begin{array}{c}\text { ECMO and } \\
\text { Ventilation Settings }\end{array}$ & $\begin{array}{l}\text { Initial Ventilation Settings (prior to ECMO): } \\
\mathrm{FiO}_{2}: 100 \% \\
\mathrm{PEEP} 20 \\
\text { Respiratory Rate: } 14 \text { breaths per minute } \\
\text { Tidal Volume: } 400 \mathrm{ml} \\
\mathrm{SpO}_{2}: \text { Never exceeded } 60 \% \\
\text { Ventilation Settings (on ECMO): } \\
\mathrm{FiO}_{2}: 40 \% \\
\mathrm{PEEP}: 5 \mathrm{~cm} \mathrm{H}_{2} \mathrm{O} \\
\text { Respiratory Rate: } 8 \text { breaths per minute } \\
\text { Tidal Volume: } 400 \text { ml } \\
\text { ECMO Settings: } \\
31 \text { French Avalon veno-venous catheter } \\
\text { Rate: } 4.56 \mathrm{~L} / \text { min } \\
\text { FiO }: 100 \% \\
\text { Sweep: } 3.5 \mathrm{~L} / \text { min } \\
\text { Mixed Venous: } 77.1 \% \\
\text { Activated Clotting Time (ACT): Above } 200 \\
\text { Duration: } 7 \text { days }\end{array}$ \\
\hline $\begin{array}{l}\text { Time to Clearance } \\
\text { of Images }\end{array}$ & $\begin{array}{l}15 \text { days from admission to final CT Chest } \\
\text { (Figure } 2 \text { \& Figure } 3 \text { ) }\end{array}$ \\
\hline Complications & None, patient made an uneventful recovery \\
\hline
\end{tabular}

PEEP and pressure support settings of mechanical ventilation were high, this patient was unable to ventilate and maintain oxygenation adequately. Therefore, it was determined that this patient should be placed on VV-ECMO which was done within one hour following endotracheal intubation. Endotracheal intubation was not associated with aspiration. 


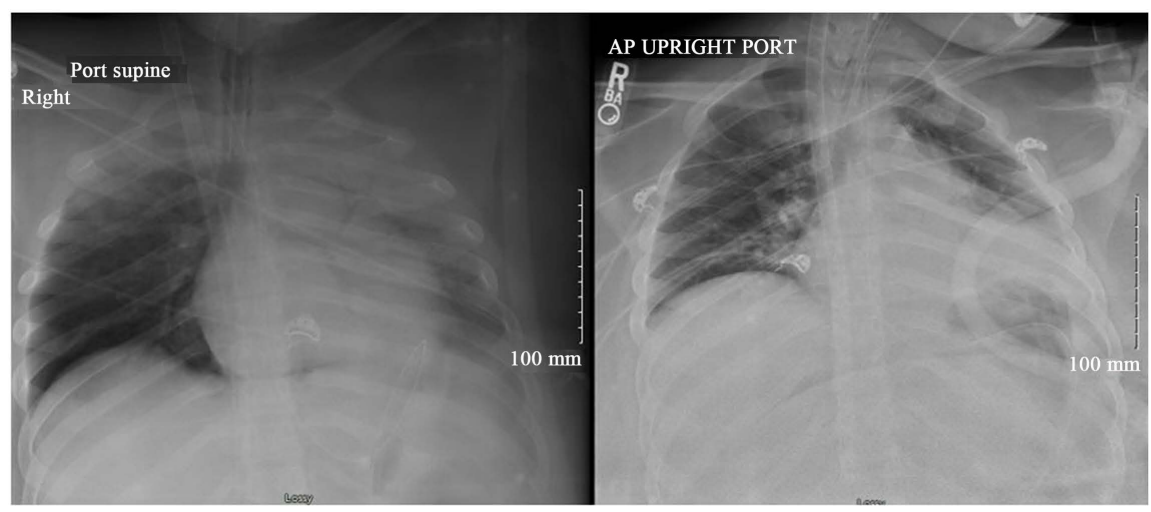

Figure 2. Chest X-rays immediately post placement of 31 French Avalon veno-venous catheter for ECMO.

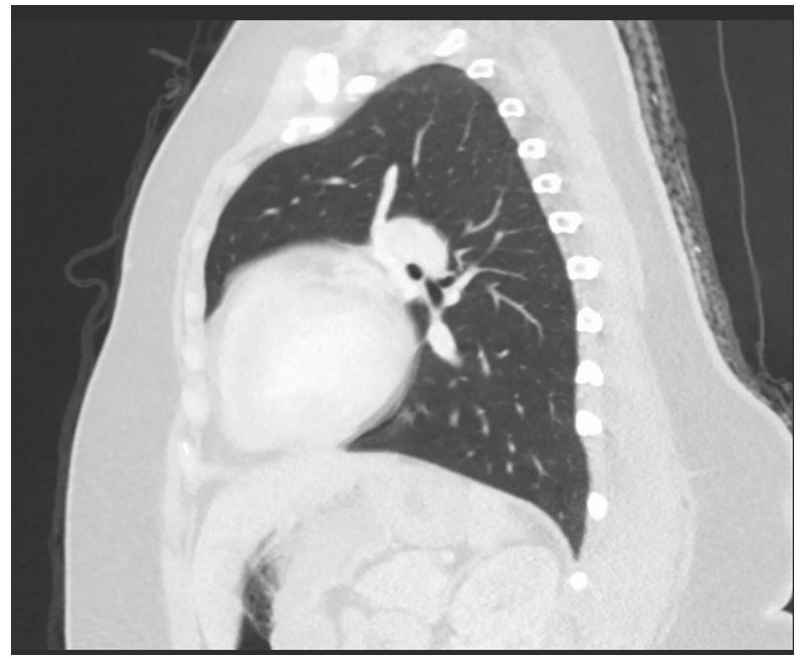

Figure 3. Sagittal chest CT post-ECMO, post-extubation showing recovery prior to discharge.

There were gradual improvements in the patient's condition following placement on VV-ECMO. The patient made an uneventful recovery, improving both clinically and radiographically.

Few case reports of diffuse lung injury caused by SC requiring mechanical ventilation have been found [10] [11] [13] [14] [15]. Many reports have focused on the depressive effects of SC on respiratory drive [12]. In these patients chest $\mathrm{x}$-rays were unremarkable because the effect of SC was on the central nervous system's control of respiratory drive rather than the lung parenchyma itself. Since 2019, few reports of SC associated diffuse lung injury requiring mechanical ventilation have been described [10] [11] [13] [16]. Of these, only one utilized ECMO as a form of life-saving bridge therapy [16]. Review of the other cases demonstrates similar bilateral alveolar infiltrates, one in which was noted to be secondary to diffuse alveolar hemorrhage [10] [11] [13] [14] [15]. There has only been one reported case of SC inhaled by water pipe method [10]. Our patient used a water pipe similar to the bucket method as described in Yamanoglu, et al., 2018 [10]. It has been proposed that a higher concentration of the heterogenous 
toxic metabolites from SC may cause a more direct injury to the lungs with this method of inhalation. In fact, synthetic marijuana potency relative to THC can be up to 660 times greater [20]. In this particular case, a similar bloody and pink, frothy aspirate suggests acute lung injury not caused by other entities [10].

This patient remained on ECMO for four days in our care with gradual clinical improvement. She was then transferred to an academic center where, after three more days, was decannulated and then self-extubated the next day. The patient was discharged one week later and made an uneventful recovery.

Acute pulmonary injury caused by SC inhalation is a rare event but is expected to become more common [7] [21]. This case demonstrates the severe life-threatening and rapid deterioration that may ensue after smoking concentrated SC through a water pipe.

Immediate recognition of impending respiratory insufficiency with the subsequent need for endotracheal intubation and provision of ECMO for continued failure of adequate ventilation and gas exchange must remain an immediate priority. With the recent increase in complications of SC reported recently, one would expect there will be many more cases to come.

Radiologic patterns characteristic of SC-induced pulmonary toxicity can be defined as diffuse, acute patches of alveolar infiltrates with patchy air bronchograms. This classic radiologic presentation is a function of bronchial endothelial injury which often presents as a diffuse centrilobular nodule with tree-in-bud pattern [7]. This response results in a pattern of injury consistent with organizing pneumonia.

Histopathologic findings of organizing pneumonia are also characteristic in patients with chronic SC associated lung injury [14]. CT radiograph may show a diffuse miliary-micronodular pattern and Chest CT may demonstrate diffuse centrilobular nodules and tree-in-bud pattern [7]. For patients who present with unexplained pulmonary infiltrates as described above, SC use should be included on the list of differential diagnoses. An appropriate history must be taken, and drug screen testing may be indicated.

Little is known regarding the etiology DAH associated with SC. In some cases, toxic metabolites have been linked to direct alveolar or bronchopulmonary injury leading to DAH [3]. These reported metabolites have been found to vary in chemical makeup and concentrations, resulting in a range of heterogeneous effects and potency. Testing for these cannabinoids is imperfect. ELISA is limited by the number of detectable metabolites and is not commercially available. Recently, a case of DAH associated with the SC metabolite UR-144, UR-144 N (4/5-hydroxypentyl) has been published [16]. Because of the direct toxic injury, steroids have been administered and may be an effective measure. Further investigation is needed.

Cannabidiol (CBD) inhalation products have become increasingly available. Common routes of inhalation include water pipes and electronic delivery (vaping) [22]. Recent reports from lay press have raised concerns that vaping CBD could be more detrimental when compared to water pipe inhalation due to un- 
known additives such as SC in the vaping solution [23].

ECMO has proven to be crucial in the management of nicotine vaping related pulmonary injuries [24]. With recent CBD vaping trends in combination with an unregulated market, early anticipation and intervention with ECMO may be crucial and possibly lifesaving going forward.

\section{Conclusion}

Acute pulmonary toxicity causing severe injury and requiring mechanical ventilation is an uncommon phenomenon. We present a case of acute respiratory distress syndrome in a 21-year-old female whose only risk factor for developing sudden hemorrhagic pulmonary edema was the recent inhalation of SC through a water pipe. The etiology of this injury is not certain and would be challenging to determine due to the numerous pneumotoxic metabolites potentially found in SC. The immediate deterioration of this patient and her dramatic improvement following ECMO suggest that early consideration of ECMO for patients with respiratory insufficiency caused by acute pulmonary injury related to SC should be considered. Indications for ECMO are evolving. Regardless of etiology, the inability to ventilate and exchange gas, particularly in a young patient without multiorgan failure, necessitates early utilization of ECMO [25] [26].

\section{Author Contributions}

Authors have either participated in the care of the patient and/or the preparation of the manuscript and have approved of the manuscript.

\section{Conflicts of Interest}

The authors declare no conflicts of interest regarding the publication of this paper.

\section{References}

[1] Law, R., Schier, J., Martin, C., Chang, A. and Wolkin, A. (2015) Centers for Disease C: Notes from the Field: Increase in Reported Adverse Health Effects Related to Synthetic Cannabinoid Use-United States, January-May 2015. Morbidity and Mortality Weekly Report, 64, 618-619.

[2] Kleiman, A., Ravichandran, A., Macaluso, C. and Brust, J. (2016) Neurologic Presentation of K2: A City Hospital Experience (P2.258).

[3] Adams, A.J., Banister, S.D., Irizarry, L., Trecki, J., Schwartz, M. and Gerona, R. (2017) "Zombie" Outbreak Caused by the Synthetic Cannabinoid AMB-Fubinaca in New York. New England Journal of Medicine, 376, 235-242. https://doi.org/10.1056/NEJMoa1610300

[4] Jack, A. (2009) The Story of Spice. The Financial Times [Internet].

[5] Zimmer, D.I., McCauley, R., Konanki, V., et al. (2019) Emergency Department and Radiological Cost of Delayed Diagnosis of Cannabinoid Hyperemesis. Journal of Addiction, 2019, Article ID: 1307345. https://doi.org/10.1155/2019/1307345

[6] Vandrey, R., Dunn, K.E., Fry, J.A. and Girling, E.R. (2012) A Survey Study to Cha- 
racterize Use of Spice Products (Synthetic Cannabinoids). Drug and Alcohol Dependence, 120, 238-241. https://doi.org/10.1016/j.drugalcdep.2011.07.011

[7] Berkowitz, E.A., Henry, T.S., Veeraraghavan, S., Staton, G.W. and Gal, A.A. (2014) Pulmonary Effects of Synthetic Marijuana: Chest Radiography and CT Findings. American Journal of Roentgenology, 204, 750-757. https://doi.org/10.2214/AJR.14.13138

[8] Winstock, A., Lynskey, M., Borschmann, R. and Waldron, J. (2015) Risk of Emergency Medical Treatment Following Consumption of Cannabis or Synthetic Cannabinoids in a Large Global Sample. Journal of Psychopharmacology, 29, 698-703. https://doi.org/10.1177/0269881115574493

[9] Winstock, A.R. and Barratt, M.J. (2013) Synthetic Cannabis: A Comparison of Patterns of Use and Effect Profile with Natural Cannabis in a Large Global Sample. Drug Alcohol Depend, 131, 106. https://doi.org/10.1016/j.drugalcdep.2012.12.011

[10] Yamanoglu, A., Cakmak, S., Celebi Yamanoglu, N.G. and Sogut, O. (2018) A New Side Effect of Synthetic Cannabinoid Use by the Bucket (Waterpipe) Method: Acute Respiratory Distress Syndrome (ARDS). Turkish Journal of Emergency Medicine, 18, 42-44. https://doi.org/10.1016/j.tjem.2017.06.001

[11] Imtiaz, M., Saha, B., Sana Ullah, U. and Saha, A. (2019) A Case of Acute Life-Threatening Pulmonary Hemorrhage from Synthetic Cannabinoid Abuse. Case Reports in Pulmonology, 2019, Article ID: 8137648. https://doi.org/10.1155/2019/8137648

[12] Alon, M.H. and Saint-Fleur, M.O. (2017) Synthetic Cannabinoid Induced Acute Respiratory Depression: Case Series and Literature Review. Respiratory Medicine Case Reports, 22, 137-141. https://doi.org/10.1016/j.rmcr.2017.07.011

[13] Adelman, M., Thorp, M. and Smith, R. (2016) Diffuse Alveolar Hemorrhage Due to K2 Inhalation. Chest, 150, 1248A. https://doi.org/10.1016/j.chest.2016.08.1361

[14] Alhadi, S., Tiwari, A., Vohra, R., Gerona, R., Acharya, J. and Bilello, K. (2013) High Times, Low Sats: Diffuse Pulmonary Infiltrates Associated with Chronic Synthetic Cannabinoid Use. Journal of Medical Toxicology, 9, 199-206. https://doi.org/10.1007/s13181-013-0288-9

[15] Loschner, A., Cihla, A., Jalai, F. and Ghamande, S. (2011) Diffuse Alveolar Hemorrhage: Add “Greenhouse Effect” to the Growing List. Chest, 140, 149A. https://doi.org/10.1378/chest.1119854

[16] Patel, M., Tormoehlen, L. and Gutteridge, D. (2018) Use of Venovenous Extracorporeal Membrane Oxygenation for Diffuse Alveolar Hemorrhage Due to Inhaled Synthetic Cannabinoids or "Spice". American Journal of Respiratory and Critical Care Medicine, 197, A6597.

[17] Allen, J., de Moore, G., Heddle, R. and Twartz, J. (2004) Cannabinoid Hyperemesis: Cyclical Hyperemesis in Association with Chronic Cannabis Abuse. GUT, 53, 1566-1570. https://doi.org/10.1136/gut.2003.036350

[18] Patterson, D.A., Smith, E., Monahan, M., et al. (2010) Cannabinoid Hyperemesis and Compulsive Bathing: A Case Series and Paradoxical Pathophysiological Explanation. The Journal of the American Board of Family Medicine, 23, 790-793. https://doi.org/10.3122/jabfm.2010.06.100117

[19] Definition Task Force A, Ranieri, V., Rubenfeld, G., et al. (2012) Acute Respiratory Distress Syndrome: The Berlin Definition. JAMA, 307, 2526-2533. https://doi.org/10.1001/jama.2012.5669

[20] Psychoyos, D. and Vinod, K.Y. (2013) Marijuana, Spice "Herbal High", and Early Neural Development: Implications for Rescheduling and Legalization. Drug Testing 
and Analysis, 5, 27. https://doi.org/10.1002/dta.1390

[21] Lapoint, J., Meyer, S., Charles, K.Y., et al. (2018) Cannabinoid Hyperemesis Syndrome: Public Health Implications and a Novel Model Treatment Guideline. Western Journal of Emergency Medicine, 19, 380. https://doi.org/10.5811/westjem.2017.11.36368

[22] Javadi-Paydar, M., Creehan, K.M., Kerr, T.M. and Taffe, M.A. (2019) Vapor Inhalation of Cannabidiol (CBD) in Rats. Pharmacology Biochemistry and Behavior, 184, Article ID: 172741. https://doi.org/10.1016/j.pbb.2019.172741

[23] Spiked Vapes and Emergency Room Visits Reveal Dark Side of CBD Craze. https://www.usatoday.com/story/news/health/2019/09/16/vaping-lung-illness-cbd-c heap-synthetic-marijuana-used-sub/2339545001

[24] Carter, T., Tucker, D., Kilic, A., Papadimos, T.J., Barlow, A. and Berry, E. (2017) Life-Threatening Vesicular Bronchial Injury Requiring Veno-Venous Extracorporeal Membrane Oxygenation Rescue in an Electronic Nicotine Delivery System User. Clinical Practice and Cases in Emergency Medicine, 1, 212-217. https://doi.org/10.5811/cpcem.2017.3.33171

[25] Makdisi, G. and Wang, I.-W. (2015) Extra Corporeal Membrane Oxygenation (ECMO) Review of a Lifesaving Technology. Journal of Thoracic Disease, 7, E166.

[26] Shaheen, A., Tanaka, D., Cavarocchi, N.C. and Hirose, H. (2016) Veno-Venous Extracorporeal Membrane Oxygenation (V V ECMO): Indications, Preprocedural Considerations, and Technique. Journal of Cardiac Surgery, 31, 248-252.

https://doi.org/10.1111/jocs. 12690 